\title{
EFFECT OF PLATELET EXTRACT ON HEMOPHILIC BLOOD
}

\author{
BY ERNEST MOND 1 AND KARL SINGER
}

\author{
(From the Department of Hematologic Research, 2 Medical Research Institute, Michael Reese \\ Hospital, Chicago)
}

(Submitted for publication July 1, 1950; accepted, October 23, 1950)

The function of platelets in the clotting process is still a matter of controversy. In Morawitz's classic formulation (1) the role of furnishing thromboplastin was attributed to them. Brinkhous, who agrees with this concept, has demonstrated that platelet-free, "quasi-hemophilic" plasma does not clot (2). According to him (2, 3 ) the thromboplastin contained in platelets is set free during clotting through the action of a plasma factor functioning as a thrombocytolysin. The fundamental defect in hemophilia is thought to be a diminution or absence of this plasma factor. Other investigators $(4,5)$, however, have maintained that the quantities of thromboplastin found in platelets are too small to be of significance in coagulation. According to Quick $(3,6)$ they liberate an enzyme, thromboplastinogenase, which interacts with the plasma factor, thromboplastinogen, to form thromboplastin. Hemophilia again is interpreted to be a deficiency of the plasma factor, i.e., a lack of substrate for the platelet enzyme. Ware and associates (7) analyzed platelet extracts and found traces of thromboplastin, an accelerator analogous to serum Ac-globulin and a factor which enhances the action of thrombin on fibrinogen.

During the study of two patients with hemophilia-like disease caused by circulating anticoagulants which seemed to inhibit either the formation or utilization of thromboplastin, we found (8) that a concentrated homogenate ${ }^{3}$ of ground-up platelets was able to restore the markedly prolonged clotting times to normal. Quick and Stefanini (9) have suggested that in hemophilia-like disease the anticoagulant may inhibit the action of the platelet enzyme on the plasma thromboplastin precursor,

\footnotetext{
1 Ruth Reader Fellow in Hematology.

2 The Department is in part supported by the Michael Reese Research Foundation and the Hematology Research Foundation. Acknowledgment is also made for support of these studies to the Hulda B. and Maurice L. Rothschild Foundation for Scientific Research.

3 For the sake of convenience the terms platelet "extract" and "homogenate" will be used interchangeably.
}

and the acceleration of clotting observed by us seemed to be attributable to an overcoming or neutralization of the anti-platelet enzyme factor by the extract. However, we observed a similar shortening of the coagulation time when such a concentrated platelet preparation was added to hemophilic blood (8), which is deficient in plasma factor but has normal platelets. It was established that these extracts had definite thromboplastic activity, and the problem presented itself whether this could account for the noted effects. It was decided, therefore, to investigate and compare the action of platelet homogenates and dilutions of tissue thromboplastin on the clotting time and prothrombin consumption time of a group of patients with hemophilia.

\section{METHODS}

\section{1) Preparation of Platelet Extract.}

A modification of the procedure described by Mann and colleagues (10) was employed. Citrated blood (one part of $1.34 \%$ sodium citrate to four parts of whole blood) is collected with an ordinary syringe and centrifuged soon after collection at 700-800 RPM for one half hour. The supernatant platelet-rich plasma is respun at the same speed for 15 minutes, removed from the few remaining red cells, and again centrifuged in Wassermann tubes at $3,000 \mathrm{RPM}$ for 30 minutes.

The platelets, which still may be contaminated with a few red and white cells, are found to form a sticky pellet at the bottom of the tubes. The supernatant plasma is poured off and measured; the pellet is dislodged and broken up with a wooden applicator and shaken vigorously with a saline-citrate solution ( $0.1 \mathrm{cc}$. of sodium citrate to $10 \mathrm{cc}$. of normal saline). The platelets are then sedimented again by centrifuging at 3,000 RPM for 10 minutes. This process of washing is repeated three more times. After the final washing the platelets are suspended in saline-citrate and triturated in a mortar for two to three minutes. The final volume of this suspension of ground-up platelets in saline-citrate is adjusted so that $1 \mathrm{cc}$. of platelet homogenate corresponds to $10 \mathrm{cc}$. of original plasma, care being taken to correct for the $20 \%$ dilution of the plasma with citrate. The platelet extract is then ready for use but can be kept in the frozen state for 24 hours without loss of potency. 


\section{2) Prothrombin Time.}

Determinations were made with the one-stage method of Quick, using a commercial preparation of thromboplastin (Maltine). Normal values range from 11 to 14 seconds.

\section{3) Clotting Time.}

The Lee-White clotting time was done always in three test tubes $(8 \times 75 \mathrm{~mm}$.) at room temperature. Values up to 20 minutes are considered to be normal (11). When the effect of various substances on the clotting time was tested, the material was placed first into each tube, $1 \mathrm{cc}$. of blood then added, the tube inverted once, and the clotting time measured in the usual manner.

\section{4) Prothrombin Consumption Time.}

This test was performed by a slight modification of Quick's (4) method. About $5 \mathrm{cc}$. of blood were drawn into an ordinary syringe with a silicone-coated needle by clean venipuncture and discarded. Then a blood sample for the test was collected in an iced, siliconized syringe through the same needle and centrifuged in iced, siliconized tubes at 1,700 RPM for 10 minutes. The plasma was tranferred in $1 \mathrm{cc}$. portions to uncoated tubes containing the substance whose effect on prothrombin consumption time was to be tested and allowed to clot at $37^{\circ} \mathrm{C}$. One hour after coagulation the clot was rimmed and the tube centrifuged at 4,500 RPM for one minute. The prothrombin consumption time was determined immediately using freshly prepared $\mathrm{BaSO}_{4}$-plasma as a source of fibrinogen. Normal values, in our hands, are above 17 seconds, signifying that more than $60 \%$ of the prothrombin activity has disappeared. Further determinations of prothrombin consumption time were made on the serum, which had been allowed to remain in contact with the clot at $37^{\circ} \mathrm{C}$, at varying intervals up to one and one half hours. There is normally a progressive lengthening of the prothrombin consumption time within this period.

\section{5) Preparation of Thromboplastin Dilutions.}

Thromboplastin (Maltine) was prepared as for the routine prothrombin time determination. The final thromboplastin solution was tested on normal oxalated plasma. When found to be satisfactory (prothrombin time of 11 to 14 seconds), the thromboplastin solution was diluted with normal saline until the desired concentrations were obtained.

\section{RESULTS}

\section{1) Determination of the Thromboplastic Activity of Platelet Extracts.}

The one-stage prothrombin time procedure of Quick was used as an index of the thromboplastic activity of platelet homogenates. $0.1 \mathrm{cc}$. of platelet extract and of increasing dilutions of thromboplastin were substituted for undiluted thromboplastin, and the "prothrombin times" determined on normal, oxalated plasmas in the usual manner. This comparison was performed separately for each platelet preparation, and their average thromboplastic activity was found to be equivalent to that of a thromboplastin dilution of approximately $1: 800$. Table I gives typical values obtained in such experiments with four different platelet extracts.

\section{2) Effect of Platelet Extracts on Clotting Time.}

Platelet extracts always were effective in shortening the clotting times of the bloods of eight hemophiliacs (Table II). Although the amount of extract used in these experiments was usually 0.3 cc., as little as $0.05 \mathrm{cc}$. was sufficient to bring the clotting times into the normal range in almost all instances. This effect cannot be attributed to contamination with either plasma or red cells, even though it has been shown that quantities of normal plasma as small as $0.001 \mathrm{cc}$., when added to $2 \mathrm{cc}$. of hemophilic blood, increase the rate of clotting considerably (12). When the clot-promoting ability of equal quantities of dilutions of fresh oxalated plasma, triturated washed red cells, and platelet extracts was compared, significant shortening of the clotting occurred only with the diluted plasma

TABLE I

Comparison of thromboplastic activity of platelet extracts and dilutions of thromboplastin on normal plasmas

\begin{tabular}{|c|c|c|c|c|}
\hline \multirow{2}{*}{ Source of thromboplastin } & \multicolumn{4}{|c|}{ "Prothrombin" time in seconds } \\
\hline & Subject A & Subject B & Subject C & Subject D \\
\hline $\begin{array}{l}\text { Thromboplastin (Maltine) undiluted } \\
\text { Thromboplastin (Maltine) } 1: 500 \\
\text { Thromboplastin (Maltine) } 1: 800 \\
\text { Thromboplastin (Maltine) } 1: 1,000 \\
\text { Thromboplastin (Maltine) } 1: 2,000 \\
\text { Platelet extracts }\end{array}$ & $\begin{array}{l}12 \\
63 \\
75 \\
80 \\
93 \\
74\end{array}$ & $\begin{array}{l}13 \frac{1}{2} \\
64 \\
72 \\
81 \\
88 \\
66\end{array}$ & $\begin{array}{l}12 \\
61 \\
71 \\
85 \\
74\end{array}$ & $\begin{array}{l}14 \\
66 \\
79 \\
94 \\
93 \\
90\end{array}$ \\
\hline
\end{tabular}


TABLE II

Effect of platelet extracts and of thromboplastin dilutions on clotting times of hemophilic blood

\begin{tabular}{|c|c|c|c|c|c|c|c|}
\hline \multirow{3}{*}{$\begin{array}{l}\text { Patient } \\
\text { no. }\end{array}$} & \multicolumn{2}{|c|}{$\begin{array}{l}\text { Effect of platelet extract } \\
\text { (clotting times in minutes) }\end{array}$} & \multicolumn{5}{|c|}{$\begin{array}{l}\text { Effect of thromboplastin dilutions } \\
\text { (clotting times in minutes) }\end{array}$} \\
\hline & \multirow{2}{*}{$\begin{array}{l}\text { Normal saline } \\
0.3 \text { cc. }\end{array}$} & \multirow{2}{*}{$\begin{array}{l}\text { Platelet extr. } \\
0.3 \mathrm{cc} \text {. }\end{array}$} & \multirow{2}{*}{$\begin{array}{c}\text { Normal } \\
\text { saline } \\
0.3 \text { cc. }\end{array}$} & \multicolumn{4}{|c|}{ Thromboplastin dilutions } \\
\hline & & & & $\begin{array}{l}1: 500 \\
0.3 \mathrm{cc}\end{array}$ & $\begin{array}{l}1: 800 \\
0.3 \mathrm{cc} .\end{array}$ & $\begin{array}{l}1: 1,000 \\
0.3 \mathrm{cc}\end{array}$ & $\begin{array}{l}1: 2,000 \\
0.3 \mathrm{cc} .\end{array}$ \\
\hline $\begin{array}{l}1 \\
2 \\
3 \\
4 \\
5 \\
6 \\
7 \\
8\end{array}$ & $\begin{array}{c}26 \frac{1}{2} \\
33 \\
35 \\
44 \\
\text { over } 150 \\
130 \\
69 \\
120\end{array}$ & $\begin{array}{r}9 \\
9 \\
15 \\
14 \\
8 \\
13 \\
17 \\
16\end{array}$ & $\begin{array}{r}23 \\
35 \\
35 \\
22 \\
130 \\
69 \\
120\end{array}$ & $\begin{array}{l}8 \\
8 \\
9 \\
8 \\
7 \\
8 \\
6\end{array}$ & $\frac{8}{15}$ & $\begin{array}{r}8 \\
9 \\
24 \\
9 \\
8 \\
21 \\
9\end{array}$ & $\begin{array}{l}11 \\
13 \\
25 \\
10 \\
34 \\
21 \\
\end{array}$ \\
\hline
\end{tabular}

and the platelet extracts. The potency of the platelet preparations was essentially unaffected by repeated washings prior to trituration, demonstrating that contamination with antihemophilic globulin was not involved (Table III).

\section{3) Effect of Thromboplastin Dilutions on Clotting} Time.

Saline thromboplastin dilutions of $1: 500$ and $1: 800$ reduced the clotting times to normal values in all instances (Table II). Higher dilutions $(1: 1,000,1: 2,000)$ were less effective in some patients but always caused a significant shortening of the clotting time. A rough quantitative relationship seems to exist between the rate of clotting and the amount of thromboplastin added.

\section{4) Effect of Platelet Extracts on Prothrombin Consumption Time.}

The prothrombin consumption time was determined on 27 separate occasions in our eight pa- tients. In five patients the values obtained never were higher than 13 seconds, whereas in three (cases 1, 3, and 4, Table IV) the prothrombin consumption time showed definite, spontaneous fluctuations, sometimes even reaching the normal range. In two instances we observed a normal prothrombin consumption time in the presence of a prolonged clotting time. The effect of platelet extracts was tested on 12 separate occasions (Table IV). A change to normal values-above 17 seconds-was obtained six times (twice with $0.2 \mathrm{cc}$., and four times with $0.4 \mathrm{cc}$.), whereas in five experiments the prothrombin consumption time was raised only slightly. The ability of equal amounts of platelet extract to produce an increased prothrombin consumption time varied in one patient (case 6) on different days. This cannot be blamed on differences in potency of the homogenates used, since extracts were found to be effective in one patient, but ineffective in another when tested simultaneously. Therefore, it seems

TABLE III

Comparison of the effect of platelet extract, triturated red cells, and diluted normal plasma on the clotting time of hemophilic blood

\begin{tabular}{|c|c|c|c|c|}
\hline \multirow{2}{*}{ Material added $(0.3 \mathrm{cc}$.) to $1 \mathrm{cc}$. of hemophilic blood } & \multicolumn{4}{|c|}{ Clotting time in minutes } \\
\hline & Subject A & Subject B & Subject C & Subject D \\
\hline $\begin{array}{l}\text { None } \\
\text { Normal saline } \\
\text { Platelet extract, washed } 3 \times \\
\text { Platelet extract, washed } 5 \times \\
\text { Platelet extract, washed } 9 \times \\
\text { Triturated, washed red cells }(1: 10) \\
\text { Diluted plasma }(1: 10) \\
\text { Diluted plasma }(1: 100)\end{array}$ & $\begin{array}{r}34 \\
33 \\
9 \\
\overline{9} \\
25 \\
24\end{array}$ & $\begin{array}{l}\overline{88} \\
18 \\
18 \\
\frac{21}{16} \\
29\end{array}$ & $\begin{array}{l}-7 \\
95 \\
14 \\
17 \\
25 \\
83 \\
14 \\
22\end{array}$ & $\begin{array}{l}-\overline{22 \frac{1}{2}} \\
12 \\
13 \frac{1}{3} \\
12 \frac{1}{2} \\
= \\
-\end{array}$ \\
\hline
\end{tabular}


TABLE IV

Prothrombin consumption time one hour after clotting with addition of various materials to 1 cc. of "native" plasma

\begin{tabular}{|c|c|c|c|c|c|c|c|c|c|c|}
\hline \multirow{3}{*}{$\begin{array}{l}\text { Patient } \\
\text { no. }\end{array}$} & \multirow{3}{*}{$\begin{array}{l}\text { Prothrombin } \\
\text { time in } \\
\text { seconds }\end{array}$} & \multicolumn{9}{|c|}{ Prothrombin consumption time in seconds } \\
\hline & & \multirow{2}{*}{$\begin{array}{l}\text { Nothing } \\
\text { added }\end{array}$} & \multirow{2}{*}{$\begin{array}{l}\text { Normal } \\
\text { saline } \\
0.2 \mathrm{cc} .\end{array}$} & \multicolumn{2}{|c|}{ Platelet extract } & \multicolumn{5}{|c|}{$0.2 \mathrm{cc}$. Thromboplastin dilutions added } \\
\hline & & & & $0.2 \mathrm{cc}$. & $0.4 \mathrm{cc}$. & $1: 200$ & $1: 500$ & $1: 800$ & $1: 1,000$ & $1: 2,000$ \\
\hline 1 & $\begin{array}{l}12 \frac{1}{2} \\
12 \\
12 \frac{1}{2} \\
-\end{array}$ & $\begin{array}{l}15 \\
17 \\
13 \\
11 \frac{1}{3}\end{array}$ & $\frac{\bar{Z}}{13}$ & $\frac{\bar{Z}}{\overline{18}}$ & $\bar{E}$ & $\bar{z}$ & $\overline{\bar{Z}}$ & $\frac{\bar{Z}}{\overline{13 \frac{1}{2}}}$ & $\frac{二}{13 \frac{1}{2}}$ & $\bar{z}$ \\
\hline 2 & $\begin{array}{l}13 \\
14 \\
-\end{array}$ & $\begin{array}{l}11 \frac{1}{2} \\
13 \\
12 \\
12\end{array}$ & $\frac{二}{12 \frac{1}{2}}$ & $\bar{z}$ & $\frac{\bar{z}}{17}$ & $\bar{z}$ & $\frac{\bar{Z}}{\overline{17 \frac{1}{2}} *}$ & $\bar{z}$ & $\frac{\bar{Z}}{13^{*}}$ & $\bar{z}$ \\
\hline 3 & $\begin{array}{l}13 \\
14 \\
12 \frac{1}{2} \\
13 \\
13\end{array}$ & $\begin{array}{l}22 \\
22 \frac{1}{2} \\
11 \frac{1}{2} \\
16 \\
13 \\
19 \dagger\end{array}$ & $\begin{array}{l}\bar{z} \\
\bar{z}\end{array}$ & $\begin{array}{l}z \\
z \\
z\end{array}$ & $\begin{array}{l}\frac{\overline{1}}{17 \frac{1}{2}} \\
\bar{z}\end{array}$ & $\begin{array}{l}= \\
\bar{z}\end{array}$ & $\begin{array}{l}\bar{z} \\
\bar{z}\end{array}$ & $\begin{array}{l}= \\
\bar{z}\end{array}$ & $\begin{array}{l}\bar{z} \\
\bar{z}\end{array}$ & $\begin{array}{l}\bar{z} \\
\bar{z}\end{array}$ \\
\hline 4 & $\begin{array}{l}11 \frac{1}{3} \\
11 \frac{1}{3} \\
-\end{array}$ & $\begin{array}{l}11 \frac{1}{2} \\
12 \\
18 \ddagger\end{array}$ & $\bar{z}$ & $\bar{z}$ & $\overline{17}$ & $\bar{z}$ & $\bar{z}$ & $=$ & $\bar{z}$ & $=$ \\
\hline 5 & $\begin{array}{l}11 \\
13 \\
-\end{array}$ & $\begin{array}{l}19 \frac{1}{2} \\
11 \\
10 \\
12 \frac{1}{2}\end{array}$ & $\frac{\overline{11 \frac{1}{2}}}{-}$ & $\begin{array}{l}\overline{15 \frac{1}{2}} \\
=\end{array}$ & $\frac{\overline{17}}{-}$ & $\underline{-18}$ & $\frac{17}{-}$ & $\begin{array}{l}\overline{18 \frac{1}{2}} \\
\overline{-}\end{array}$ & $\frac{\overline{16}}{-}$ & $\begin{array}{l}z \\
z\end{array}$ \\
\hline 6 & $\frac{11 \frac{1}{2}}{11 \frac{1}{2}}$ & $\begin{array}{r}10 \frac{1}{2} \\
10 \frac{1}{2} \\
9 \frac{1}{2}\end{array}$ & $\frac{10 \frac{1}{2}}{9 \frac{1}{2}}$ & $\begin{array}{l}23 \frac{1}{2} \\
14 \\
13 \frac{1}{2}\end{array}$ & $\frac{\overline{1}}{14 \frac{1}{2}}$ & $\overline{\overline{14}}$ & $\begin{array}{l}\overline{12} \\
11\end{array}$ & $\frac{\bar{Z}}{10 \frac{1}{2}}$ & $\begin{array}{l}\overline{11} \\
11\end{array}$ & $\overline{10 \frac{1}{2}}$ \\
\hline 7 & $\underline{13 \frac{1}{2}}$ & $\begin{array}{l}\text { no clot } \\
\text { no clot }\end{array}$ & $\frac{9}{-}$ & $\begin{array}{l}13 \frac{1}{2} \\
16\end{array}$ & 15 & $=$ & $10 \frac{1}{2}$ & 10 & $10 \frac{1}{2}$ & 11 \\
\hline 8 & $\begin{array}{l}14 \\
13 \frac{1}{2}\end{array}$ & $\begin{array}{c}\text { no clot } \\
10\end{array}$ & $\begin{array}{l}11 \\
10\end{array}$ & $\begin{array}{l}14 \frac{1}{2} \\
15\end{array}$ & $\begin{array}{l}15 \frac{1}{2} \\
16\end{array}$ & $\overline{23}$ & $\begin{array}{l}12 \\
20 \frac{1}{2}\end{array}$ & $\begin{array}{l}15 \frac{1}{2} \\
10 \frac{1}{2}\end{array}$ & $15 \frac{1}{2}$ & $11 \frac{1}{2}$ \\
\hline
\end{tabular}

* Only $0.5 \mathrm{cc}$. of plasma used

Clotting time 35 minutes

$\mp$ Clotting time 22 minutes

likely that the irregular responses are determined by variables present in the plasmas.

\section{5) Effect of Thromboplastin Dilutions on the Prothrombin Consumption Time.}

Thromboplastin in dilutions of $1: 1,000$ or $1: 2,000$, added to hemophilic plasma, had little effect. Larger concentrations (1:200 to $1: 800)$, however, were capable of producing a normal prothrombin consumption time at times. No parallelism appeared to exist between the ability of dilute solutions of thromboplastin to shorten the coagulation time and to increase the prothrombin consumption time. A quantity of thromboplastin, which clots hemophilic blood with normal speed, may be unable to affect the prothrombin consumption time in the same patient. These results are to be expected, since it is known that the prothrombin consumption time of hemophilic bloodwhich has clotted because of contamination with tissue thromboplastin during venipuncture-may be pathologic in the presence of a normal clotting time (13). Again it is to be noted that individual patients showed marked differences in the extent to which thromboplastin dilutions could alter their prothrombin consumption time.

\section{DISCUSSION}

Our experiments showed that concentrated aqueous homogenates of human platelets con- 
sistently reduced the clotting times to normal in eight hemophilic subjects. The effect on the prothrombin consumption time, however, was not always significant. Platelet extract was found to possess a thromboplastic activity equivalent to that of a dilution of lung thromboplastin of about $1: 800$ as measured with the one-stage "prothrombin time" technique. Thromboplastin solutions of this potency exerted approximately the same effect on the clotting and prothrombin consumption times as the platelet preparations. These findings seem to indicate that the platelet extracts most likely acted by virtue of their thromboplastic activity. We choose this term since the nature of "thromboplastin" is not clearly defined at present. Many materials exhibit thromboplastic activity, but the responsible agents are not necessarily identical. At least two thromboplastins with different chemical properties have been found in lung and brain tissues, respectively (14).

Previog investigations have demonstrated that platelets contain traces of thromboplastin $(4,5,7$, $15)$, an accelerator analogous to serum Ac-globulin $(7,15)$, and a factor enhancing the action of thrombin on fibrinogen (7). It is unlikely that the platelet accelerator accounts for the observed results, since it has been shown that purified Acglobulin does not influence significantly the clotting time of hemophilic blood (16). A potentiation of the action of thrombin on fibrinogen does not explain the increased prothrombin consumption time which was observed on several occasions and, therefore, cannot be the primary mechanism by which the platelet homogenate exerts its effect.

Other clotting factors also can be ruled out. Thrombin is not present in the platelet homogenates since they do not clot $\mathrm{BaSO}_{4}$-plasma (17). No serum prothrombin conversion accelerator has been found in platelet extracts (18). Plasma antihemophilic globulin is removed by repeated washings during the preparation of the platelet extracts. It does not appear reasonable that thromboplastinogenase, the platelet enzyme specifically postulated to interact with the plasma factor thromboplastinogen (antihemophilic globulin), should have a direct activating effect on prothrombin. This would have to be assumed since no, or very little, thromboplastinogen can be considered to be present in hemophilic blood. By exclusion, therefore, it appears that platelet extract acted by virtue of its thromboplastic activity. Our comparative studies with dilutions of tissue thromboplastin, while not furnishing direct evidence, also strengthen this interpretation by demonstrating that only very small amounts of thromboplastin are fully capable of producing all the effects noticed with platelet extract.

Most investigators agree that interaction of both platelet and plasma factors is necessary to form an active thromboplastin for normal clotting. Conley and co-workers (19) have shown that "complete" clotting-as measured by normal clotting and normal prothrombin consumption timestakes place only when both factors are present. In hemophilia the plasma factor is absent or decreased, while the platelets now are considered to be normal (2-4); in severe thrombocytopenia the picture is reversed (20). In both conditions the prothrombin consumption time is usually abnormal; in hemophilia the clotting time is increased, but in thrombocytopenia it is within normal limits. In the latter disorder this finding is ascribed to either release of sufficient thromboplastinogenase by the few remaining platelets (3, 4 ) or direct activation of the plasma thromboplastin precursor by glass surfaces (21). In our experiments platelet extracts on several occasions produced both normal clotting and prothrombin consumption times in hemophilic subjects in whom the plasma factor was absent or markedly decreased. Since the extract also was free of this latter factor, it must have provided in these instances the end product of the interaction of platelet and plasma factors, i.e. thromboplastic activity.

Patek and Stetson (22), on adding a suspension of platelets of the same concentration as that found in normal plasma, observed no effect on the clotting time of hemophilic blood. This apparent discrepancy with our data may be explained by considering that the platelet preparations used in our experiments were 1) triturated and 2) 200 times more concentrated than theirs. It does not seem permissible to apply directly our interpretation of the effect of the extracts to the function of platelets in vivo.

Most of our data show a lack of parallelism between the changes in the clotting and the prothrombin consumption times, regardless of whether tissue thromboplastin or platelet homogenate was the agent studied. In other words, while either 
reagent uniformly accelerated clotting, the "consumption of prothrombin" often was not increased significantly. Our data also suggest that patients with hemophilia show definite fluctuations in their clotting status. This is indicated by spontaneous variations in their clotting and prothrombin consumption times when tested repeatedly over prolonged periods in the absence of hemorrhage or treatment with transfusions. It is well known that hemophiliacs may exhibit periods of quiescence of bleeding manifestations to be followed by intervals marked by hemorrhages of varying severity (23). If it is assumed that these clinical and laboratory observations reflect differences in the patient's ability to form thromboplastin, this mechanism can be invoked to offer an explanation for the apparent inconsistencies of our observations. Both platelet extract and dilutions of thromboplastin supply thromboplastin in addition to that produced by the patient himself. It depends on the patient's own thromboplastin production-which does not seem to be constant-whether this extraneously furnished thromboplastin is sufficient to give a normal "consumption of prothrombin." Likewise, the occasional normal values of the prothrombin consumption time, which have been observed also by others (24), could be a reflection of a temporary improvement in the patient's clotting status. It is to be emphasized, therefore, that a normal prothrombin consumption time, even in the absence of therapy, does not exclude the diagnosis of hemophilia.

Considerable difference of opinion exists about what actually is being measured when the "prothrombin consumption time" is determined. It has been stated $(18,25)$ that during coagulation besides the disappearance of prothrombin, which lengthens the prothrombin time of the serum, accelerator factor(s) evolve, which shorten it. The release of adsorbed thrombin from the fibrin meshwork also may influence this value (26). However, even when these mechanisms are taken into consideration we are at a loss to explain our two observations of a normal prothrombin consumption time in the presence of a prolonged coagulation time.

\section{SUMMARY}

1. Addition of a concentrated homogenate of ground-up platelets consistently reduces the clot- ting times of hemophilic bloods to normal. The prothrombin consumption time is increased regularly but not always significantly.

2. These effects can be explained most satisfactorily by attributing them to the thromboplastic activity of the platelet preparations.

3 . When tested repeatedly over prolonged periods hemophiliacs, in the absence of therapy, may occasionally show a normal prothrombin consumption time. It is postulated that the fluctuations in the clotting status may reflect variations in the patient's ability to produce thromboplastin.

\section{REFERENCES}

1. Morawitz, P. D., Beiträge zur Kenntnis der Blutgerinnung. Deutsches Arch. f. klin. Med., 1904, 79, 215.

2. Brinkhous, K. M., Clotting defect in hemophilia; deficiency in a plasma factor required for platelet utilization. Proc. Soc. Exper. Biol. \& Med., 1947, 66, 117.

3. Blood clotting and allied problems. Trans. 2nd Conference Jan. 24-25, 1949, New York. Josiah Macy, Jr. Foundation, New York, $1950^{\circ}$.

4. Quick, A. J., Studies on the enigma of the hemostatic dysfunction in hemophilia. Am. J. M. Sc., 1947, 214, 272.

5. Copley, A. L., and Houlihan, R. B., Studies on platelets. VII. The agglutination of platelets isolated from human, dog, and swine blood. Blood, Spec. Issue, 1947, 1, 182.

6. Quick, A. J., The coagulation mechanism with specific reference to the interpretation of prothrombin time and a consideration of the prothrombin consumption time. Am. J. Clin. Path., 1949, 19, 1016.

7. Ware, A. G., Fahey, J. L., and Seegers, W. H., Platelet extracts, fibrin formation and interaction of purified prothrombin and thromboplastin. Am. J. Physiol., 1948, 154, 140.

8. Singer, K., Mond, E., Hyman, J., and Levy, R. C. Circulating anticoagulants in hemophilia and in hemophilia-like disease. Blood, in press.

9. Quick, A. J., and Stefanini, M., Activation of plasma thromboplastinogen and evidence of an inhibitor. Proc. Soc. Exper. Biol. \& Med., 1948, 67, 111.

10. Mann, F. D., Hurn, M., and Magath, T. B., Observations on the conversion of prothrombin to thrombin. Proc. Soc. Exper. Biol. \& Med., 1947, $66,33$.

11. Estren, S., Medal, L. S., and Dameshek, W., Pseudohemophilia. Blood, 1946, 1, 504.

12. Alexander, B., and Landwehr, G., Studies on hemophilia. II. The assay of the antihemophilic clotpromoting principle in normal human plasma with some observations on the relative potency of certain plasma fractions. J. Clin. Invest., 1948, 27, 98. 
13. Quick, A. J., and Favre-Gilly, J. E., The prothrombin consumption test: its clinical and theoretic implications. Blood, 1949, 4, 2181.

14. Gerber, C. F., and Blanchard, E. W., Synergism of thromboplastin extracts from brain and lung. Federation Proc., 1950, 9, 48.

15. McClaughry, R. I., and Seegers, W. H., Prothrombin, thromboplastin, Ac-globin and platelet accelerator: quantitative interrelationships. Blood, 1950, 4, 303.

16. Ferguson, J. H., and Lewis, J. H., "Accelerator globulin" and "antihemophilic globulin" in thrombin formation from aged prothrombin and in hemophilic blood. Proc. Soc. Exper. Biol. \& Med., 1948, 67, 228.

17. Mond, E., and Singer, K., Unpublished data.

18. deVries, A., Alexander, B., and Goldstein, R., A factor in serum which accelerates the conversion of prothrombin to thrombin: I. Its determination and some physiologic and biochemical properties. Blood, 1949, 4, 247.

19. Conley, C. L., Hartmann, R. C., and Morse, W. I., II. The clotting behavior of human "platelet-free" plasma: evidence for the existence of "plasma thromboplastin." J. Clin. Invest., 1949, 28, 340.

20. Quick, A. J., Shanberge, J. N., and Stefanini, M.,
The coagulation defect in thrombocytopenic purpura. J. Lab. \& Clin. Med., 1949, 34, 761.

21. Hartmann, R. C., Conley, C. L., and Lalley, J. S., Studies on the initiation of blood coagulation. I. The relationship of platelets to the clot-promoting effect of glass surfaces. Bull. Johns Hopkins Hosp., 1949, 85, 231.

22. Patek, A. J., and Stetson, R. P., Hemophilia. I. The abnormal coagulation of the blood and its relation to the blood platelets. J. Clin. Invest., 1936, 15, 531.

23. Frommeyer, W. B., Jr., Epstein, R. D., and Taylor, F. H. L., Refractoriness in hemophilia to coagulation-promoting agents: whole blood and plasma derivatives. Blood, 1950, 5, 401.

24. Quick, A. J., Pediatric aspects of hemophilia. Pediatrics, 1949, 3, 312.

25. Alexander, B., deVries, A., and Goldstein, R., A factor in serum which accelerates the conversion of prothrombin. II. Its evolution with special reference to the influence of conditions which affect blood coagulation. Blood, 1949, 4, 739.

26. Quick, A. J., and Favre-Gilly, J. E., Fibrin, a factor influencing the consumption of prothrombin in coagulation. Am. J. Physiol., 1949, 158, 387. 